\title{
EDITORIAL
}

\section{COLOMBIA MÉDICA Y LA FACULTAD DE SALUD ¿UNA NUEVA ERA?}

La Revista Colombia Médica se adscribe con este primer número de 2009 a la Facultad de Salud de la Universidad del Valle. Pero desde su creación ha sido la revista de nuestra Facultad, porque fue concebida, editada y dirigida por profesores de la misma. La pasión, la dedicación y los sueños de generaciones de investigadores, evaluadores, docentes y estudiantes pueden leerse en sus páginas desde hace 40 años, y el rigor académico impreso por sus creadores le permiten a la revista estar clasificada por Colciencias en la categoría A2, y haber sido incluida en el exigente índice del ISI (Web of Knowledge Science Citation Index Expanded).

La Corporación Editora Médica del Valle fundó y mantuvo durante este tiempo a Colombia Médica, como una publicación científica de la Facultad de Salud de la Universidad del Valle. De esta manera, el traslado formal de la revista a nuestra institución, además de un nuevo acto de generosidad de quienes integran la citada Corporación, es un paso natural en la vida de la revista, toda vez que su cuna ha sido la Facultad y sus creadores y animadores los docentes de la misma.

Colombia Médica continuará con la filosofía que distingue a la Facultad, siendo escuela de formación que mantenga la tradición investigativa en las nuevas generaciones y estimule una mayor productividad científica en los indicadores de excelencia académica de los programas de pregrado y postgrado de la institución, pero conservando rigurosos criterios de escogencia y evaluación en la selección de los materiales que se publiquen, para que sean sólo las mejores contribuciones nacionales y extranjeras, las que continúen nutriendo cada fascículo.

Por último, y en nombre del Consejo de la Facultad, agradezco a la Corporación Editorial Médica del Valle por su impecable labor; al Doctor Oscar Rojas Rentería, Director de la Revista; a su Director Honorario, Doctor Rodrigo Guerrero Velasco, y de manera especial a los editores de la publicación, doctores Francisco Falabella, Pablo Barreto y Guillermo Llanos, quienes durante cuatro décadas, con su trabajo silencioso, desinteresado y admirable, acrecentaron este invaluable bien. Un reconocimiento especial a la señora Dilia Franz, quien hasta su reciente jubilación, dedicó con ahínco su vida profesional a Colombia Médica.

Liliana Arias-Castillo, $M D$

Decana

Facultad de Salud, Universidad del Valle e-mail:decanosalud@univalle.edu.co 